\title{
Production of biodiesel fuel from canola oil with dimethyl carbonate using an active sodium methoxide catalyst prepared by crystallization
}

\author{
Takami Kaia, Goon Lum Maka, Shohei Wada ${ }^{a}$, Tsutomu Nakazato ${ }^{a}$, Hirokazu \\ Takanashi $^{b}$, Yoshimitsu Uemura ${ }^{c}$ \\ ${ }^{a}$ Department of Chemical Engineering, Kagoshima University, 1-21-40 Korimoto, \\ Kagoshima 890-0065, Japan \\ ${ }^{\mathrm{b}}$ Department of Chemistry, Biotechnology, and Chemical Engineering, Kagoshima \\ University, 1-21-40 Korimoto, Kagoshima 890-0065, Japan \\ ${ }^{\mathrm{c}}$ Universiti Teknologi Petronas, Bandar Seri Iskandar, 31750 Tronhoh, Perak, Malaysia \\ *Corresponding author:Tel.:+81992858361;fax: +81992858361. \\ E-mail address: t.kai@ cen.kagoshima-u.ac.jp (T.Kai)
}

\begin{abstract}
In this study, a novel method for the production of biodiesel under mild conditions using fine particles of sodium methoxide formed in dimethyl carbonate (DMC) is proposed. Biodiesel is generally produced from vegetable oils by the transesterification of triglycerides with methanol. However, this reaction produces glycerol as a byproduct, and raw materials are not effectively utilized. Transesterification with DMC has recently been studied because glycerol is not formed in the process. Although solid-state sodium methoxide has been reported to be inactive for this reaction, the catalytic activity dramatically increased with the preparation of fine catalyst powders by crystallization.
\end{abstract}


The transesterification of canola oil with DMC was studied using this catalyst for the preparation of biodiesel. A conversion greater than $96 \%$ was obtained at $65{ }^{\circ} \mathrm{C}$ for $2 \mathrm{~h}$ with a 3:1 molar ratio of DMC and oil and $2.0 \mathrm{wt} \%$ catalyst.

Keywords: Transesterification; Biodiesel; Dimethyl carbonate; Sodium methoxide

\section{Introduction}

The worldwide use of biodiesel fuel has increased over the last few decades because of environmental benefits of biodiesel. Many studies have been performed, and many review papers have been published on the subject. Raw materials of biodiesel are usually vegetable oils, which contain fatty acid triglycerides. Triglycerides are transformed to fatty acid methyl esters (FAMEs) by transesterification with methanol. Although various reaction methods have been proposed, the main industrial production method is the alkali-catalyzed homogeneous process. In this method, catalysts such as $\mathrm{NaOH}, \mathrm{KOH}$, and $\mathrm{NaOCH}_{3}$ are dissolved in methanol and used for the reaction. The methanolysis of triglycerides yields glycerol, which does not homogeneously mix with biodiesel fuels. Approximately $10 \mathrm{wt} \%$ of the product mixture produced is glycerol. The amount of glycerol byproduct has increased with an increase in biodiesel production, which has led to a decrease in the price of purified glycerol (Ayoub and Abdullah, 2012). In the alkali-catalyzed homogeneous process, the glycerol produced contains alkali metals. In small-scale plants, the glycerol byproduct cannot be utilized, and is treated as industrial waste. In large-scale plants, the glycerol byproduct can potentially be utilized as a chemical raw material. However, this requires purification processes in addition to glycerol conversion. If glycerol is not formed as a byproduct in biodiesel plants, the biodiesel production process will be much more efficient. 
It was reported that a methyl ester phase was obtained without glycerol production by using dimethyl carbonate (DMC) instead of methanol (Fabbri et al., 2007). The methyl ester phase of DMC-biodiesel contains fatty acid glycerol carbonate monoesters (FAGCs) in addition to FAMEs. Glycerol carbonate and glycerol dicarbonate are also formed as byproducts but only in low concentrations (Fabbri et al., 2007). Since FAGCs are dissolved in the methyl ester-phase, the product can be used as fuel without separation (Notari and Ribetti, 2004).

Several studies have been published on transesterification using DMC by supercritical, enzymatic, and chemical methods. The supercritical method is advantageous because transesterification rapidly occurs in a non-catalytic manner. Although this method was originally developed for the reaction with methanol, DMC can be used instead of methanol (Ilham and Saka, 2009, 2010, 2011, 2012; Tan et al., 2010). However, high temperatures (above $300{ }^{\circ} \mathrm{C}$ ) and pressures (above $15 \mathrm{MPa}$ ) are required for this method. As pointed out by Ang et al. (2014), higher energy consumption is the weakness of supercritical technology. In addition, the higher cost of reactor vessels is another disadvantage. The enzyme-catalyzed reaction can be performed under mild conditions. Immobilized lipase Novozym 435 has been used as a catalyst in the enzyme-catalyzed transesterification using DMC (Su et al., 2009; Zhang et al., 2010a; Seong, 2011; Min and Lee, 2011; Jung, 2012; Lee et al., 2013; Go et al., 2013; Gharat and Rathod, 2013; Jo et al., 2014). The optimum reaction temperature was in the range between $40{ }^{\circ} \mathrm{C}$ and $60{ }^{\circ} \mathrm{C}$. The main limitation of this method is the long reaction time (Tan et al., 2010). Therefore, the reactor size must be increased for industrial production, and a catalyst amount greater than approximately $10 \mathrm{wt} \%$ is required.

In the conventional process for producing $\mathrm{MeOH}-$ biodiesel, alkali catalysts are typically used. If these catalysts can be used for the production of DMC-biodiesel, the 
existing facilities are available, and production cost can be reduced. Zhang et al. (2010b) used $\mathrm{KOH}$ to lower the production cost for future industrial applications. A maximum FAME yield of $96.2 \%$ was obtained when the reaction time was $8 \mathrm{~h}$, catalyst amount was $8.5 \mathrm{wt} \%$ (based on the oil weight), molar ratio of DMC to palm oil was 9:1 (0.96 w/w), and temperature was $75^{\circ} \mathrm{C}$. The method required more $\mathrm{KOH}$ than the conventional method to produce $\mathrm{MeOH}-$ biodiesel, and the reaction time was longer. Panchal et al. (2013) also reported the activity of the KOH catalyst, and they achieved a maximum conversion of $96 \%$ when the temperature was $90{ }^{\circ} \mathrm{C}$, reaction time was $6 \mathrm{~h}$, catalyst amount was $4 \mathrm{wt} \%$, and weight ratio of DMC to oil was $3: 1$, meaning that the molar ratio of DMC to oil was approximately 30:1. Thus, the molar ratio was about 10 times larger than that used by Zhang et al. (2010b). Fabbri et al. (2007) used $\mathrm{NaOCH}_{3}(30 \%$ in methanol) for the transesterification of soybean oil with DMC, and the conversion was greater than $99 \%$. The reaction temperature was $90{ }^{\circ} \mathrm{C}$, reaction time was $6 \mathrm{~h}$, catalyst amount was $0.83 \mathrm{wt} \%$, and the molar ratio of DMC to oil was approximately 8 (DMC/oil, $0.81 \mathrm{w} / \mathrm{w})$.

In previous studies using alkali catalysts, a high yield of FAMEs has not been achieved under mild conditions such as those used in the production of $\mathrm{MeOH}-$ biodiesel. Those conditions typically involve 1-2 wt\% alkali catalysts, reaction times of approximately $2 \mathrm{~h}$, reaction temperatures below $60{ }^{\circ} \mathrm{C}$, and a low ratio of DMC to oils. However, these mild reaction conditions will be important for utilizing existing production facilities and suppressing the consumption of DMC and catalysts. In this study, a new catalyst preparation method was proposed for $\mathrm{NaOCH}_{3}$. The effects of reaction conditions on the conversion of oil were studied to obtain the optimum conditions.

\section{Experimental}


Fresh commercial canola oil was used as a reactant. The main components of this oil are triacylglycerol esters of oleic acid and linoleic acid with glycerol. Anhydrous methanol, DMC, $\mathrm{NaOCH}_{3}$, and other chemical reagents were purchased from Kanto Kagaku Co. (Tokyo, Japan).

The reaction was performed in a $100 \mathrm{~mL}$ glass batch reactor equipped with a heat exchanger to condense and return the DMC vapor to the reactor. The reaction temperature was maintained at a prescribed temperature using a constant temperature bath, and the reactants were stirred by a magnetic stirrer $(600 \mathrm{rpm})$. The molar ratio of DMC to vegetable oil was varied from 2:1 to 10:1. Since the average molecular weight of vegetable oil was not obtained, the molecular weight of the oil was approximated by $885.4 \mathrm{~g}$, weight of triolein. When the ratio was 2:1, the amount of DMC was two times the stoichiometric value of the reaction of FAGC formation. The catalyst amount was varied from 1.0 to $15 \mathrm{wt} \%$ based on oil weight. The reaction time was $2 \mathrm{~h}$ for each batch operation under standard conditions.

When chemical reagents were used as catalysts, powdered reagents were added to the reactant mixtures since the reagents were not dissolved in DMC. In this study, a new catalyst preparation method using crystallization was proposed. In this case, the catalyst was prepared as follows. $\mathrm{NaOCH}_{3}$ was dissolved in methanol by stirring at room temperature. Subsequently, DMC was added to the solution. Since $\mathrm{NaOCH}_{3}$ is not soluble in $\mathrm{DMC}, \mathrm{NaOCH}_{3}$ crystallized as more DMC was added to the solution. The fine particles of $\mathrm{NaOCH}_{3}$ were suspended in the single-phase solution of methanol and DMC. After DMC was added, methanol was removed by vacuum distillation at room temperature. The pressure was carefully controlled to avoid bumping and was slowly reduced when the pressure was below 100 mbar. After methanol was removed, the slurry of $\mathrm{DMC}$ and $\mathrm{NaOCH}_{3}$ was mixed with vegetable oil and transesterification was 
performed.

After the reaction, the solid catalyst separated from the liquid phase was analyzed by a high-performance liquid chromatography system (Shimadzu Corporation, Kyoto, Japan) equipped with a gel permeation chromatography column (GPC-801, Shimadzu Corporation). The acid value was determined by titration with $\mathrm{KOH}$ and the water content was measured using the Karl Fisher titration method.

\section{Results and discussion}

\subsection{Powdered alkali catalyst}

Because $\mathrm{KOH}$ and $\mathrm{NaOCH}_{3}$ are generally used for the transesterification reaction with methanol, they were tested as catalysts in this study. When $8.5 \mathrm{wt} \%$ of $\mathrm{KOH}$ catalyst was used, the conversion was only $2 \%$ after $4 \mathrm{~h}$ at $85^{\circ} \mathrm{C}$ with a $10: 1$ molar ratio of DMC to oil. This result shows that the amount of $\mathrm{KOH}$ and/or methanol must be substantially increased to achieve high conversion. However, it is unrealistic to significantly increase the amount of catalysts and methanol in industrial processes.

When $\mathrm{NaOCH}_{3}(28 \%$ in methanol) was used, methanolysis proceeded since methanol was present in the reactant mixture, and glycerol was produced. To prevent glycerol formation, a heterogeneous reaction was performed using powdered $\mathrm{NaOCH}_{3}$ purchased as a reagent. For the reaction, $\mathrm{NaOCH}_{3}$ was added to the mixture of canola oil and DMC. The conversion of the oil was approximately $99 \%$ after $4 \mathrm{~h}$. The molar ratio of DMC to oil was $10: 1$, the reaction temperature was $85^{\circ} \mathrm{C}$, and the catalyst amount was $8.5 \mathrm{wt} \%$. Fig. 1 shows the effect of catalyst amount on oil conversion when the ratio of DMC to oil was reduced to $3: 1$. To increase the conversion to approximately $100 \%, 15 \mathrm{wt} \%$ of the catalyst was required when the ratio of DMC to oil was 3:1. In the conventional production of biodiesel with methanol, the amount of alkali catalyst is usually below 2.0 
wt $\%$. This indicates that powdered $\mathrm{NaOCH}_{3}$ is unsuitable for industrial use for the production of DMC-biodiesel because of its low activity.

A high conversion was established by increasing the molar ratio of DMC to oil even when the amount of catalyst was reduced. In a previous study (Panchal et al., 2013), high conversion could be established by increasing the molar ratio of DMC to oil above 30 when $\mathrm{KOH}$ was used. However, since DMC dissolves in FAMEs and more energy is required to remove unreacted DMC from the produced fuels, the use of excessive amounts of DMC is undesirable.

Usually the reaction rate can be increased by increasing reaction the temperature. However, the temperature could not be increased over $90{ }^{\circ} \mathrm{C}$ under atmospheric pressure, because the boiling point of DMC is $90{ }^{\circ} \mathrm{C}$. Fabbri et al. (2007) mentioned that pure $\mathrm{NaOCH}_{3}$ is inactive for transesterification with DMC because $\mathrm{NaOCH}_{3}$ is solid and does not dissolve in vegetable oils and DMC. This may be the reason that there are very few reports concerning DMC-biodiesel production via alkali-catalyzed transesterification.

\subsection{Crystallized catalyst}

\subsubsection{Preparation of catalyst by crystallization}

The reaction rate of liquid--solid catalyst reactions generally increases with increasing surface area of solid catalysts. Therefore, reaction activity will be increased by producing very fine particles of $\mathrm{NaOCH}_{3}$. In this study, a fine powder of $\mathrm{NaOCH}_{3}$ was prepared by the crystallization of $\mathrm{NaOCH}_{3}$ after it was dissolved into methanol as described in the experimental section. The size of the crystallized catalyst was less than $10 \mu \mathrm{m}$, and the size of the powdered catalyst was between 40 and $300 \mu \mathrm{m}$.

As shown in Fig. 1, the conversion after $2 \mathrm{~h}$ was only $33 \%$ for the unprocessed 
powdered catalyst when the molar ratio of DMC to oil was 3:1 and catalyst weight was 5 wt $\%$ at $85{ }^{\circ} \mathrm{C}$. On the other hand, the activity of the crystallized catalyst was very high under the same conditions. The conversion after $1 \mathrm{~h}$ was approximately $100 \%$ even though the temperature was decreased to $65^{\circ} \mathrm{C}$. Thus, catalytic activity was dramatically increased by the crystallization method.

\subsubsection{Effects of molar ratio of DMC to oil}

The conversion increases when the ratio of DMC to oil is increased. Fig. 2 (a) shows the change in conversion when the catalyst weight was $1.5 \mathrm{wt} \%$ at $65^{\circ} \mathrm{C}$. As described above, one of the purposes of this study was to reduce excessive amounts of DMC. Therefore, the molar ratio range was set below 4:1. This figure shows that the conversion increased with the molar ratio. Oil conversion was more than $90 \%$ after $1.5 \mathrm{~h}$ when the molar ratio was $4: 1$. Considering that the catalyst amount was $1.5 \mathrm{wt} \%$, the activity of the crystallized catalyst was sufficient.

\subsubsection{Effect of catalyst amount}

It is better to decrease the catalyst weight for practical use from a cost standpoint. The effect of catalyst weight on the conversion was studied. The maximum catalyst amount was $5 \mathrm{wt} \%$ in the experiment. The molar ratio of DMC to oil was 3:1, and the reaction temperature was $65^{\circ} \mathrm{C}$. As shown in Fig. 2 (b), the conversion increased with increasing catalyst weight, and the conversion was more than $96 \%$ after 2 when the catalyst amount was more than $2.0 \mathrm{wt} \%$.

\subsubsection{Effect of temperature}


The effect of temperature on the conversion was evaluated when the catalyst amount was $1.5 \mathrm{wt} \%$ and the molar ratio of DMC to oil was 3:1. Since the intrinsic reaction rate generally increased with temperature, the conversion at the initial stage of the reaction increased with reaction temperature. However, the conversion after $1 \mathrm{~h}$ did not increase with temperature when the reaction temperature was $85{ }^{\circ} \mathrm{C}$. On the other hand, when the reaction temperature was $45^{\circ} \mathrm{C}$, the conversion gradually increased with time and exceeded the conversion at $85{ }^{\circ} \mathrm{C}$ after $6 \mathrm{~h}$.

A liquid phase was observed inside the upper part of the reactor and condenser. Since the amount of this condensed liquid increased with reaction temperature, this must be DMC that escaped as vapor from the reaction solution. Therefore, the DMC concentration in the liquid phase decreased with increasing temperature, and consequently reduced the reaction rate at higher temperatures. Therefore, high temperature near the boiling point of $\mathrm{DMC}\left(90^{\circ} \mathrm{C}\right)$ was unsuitable to establish high conversion of oils when the reaction was performed under atmospheric pressure in an open system. Considering these results, the optimum conditions were a molar ratio of DMC to oil of 3:1, $2.0 \mathrm{wt} \%$ catalyst, and $65^{\circ} \mathrm{C}$.

\subsubsection{Effects of moisture content and acid value}

$\mathrm{NaOCH}_{3}$ forms methanol and $\mathrm{NaOH}$ by reaction with water. As described above, since the catalytic activity of $\mathrm{NaOH}$ is very small, this reaction is undesirable. However, the raw material usually contains a small amount of water in addition to free fatty acids (FFAs). Therefore, the effects of moisture content and acid value on the conversion were measured with $2.0 \mathrm{wt} \%$ catalyst.

The results showed that the conversion was not affected by the moisture content when it was below $0.1 \mathrm{wt} \%$. In addition, when the acid value was lower than $2.0 \mathrm{mg} \mathrm{KOH} / \mathrm{g}$ oil, 
the effect of FFAs was insignificant. The conversion was above $96 \%$ when moisture content was $0.13 \mathrm{wt} \%$ and the acid values were $2.0 \mathrm{mg} \mathrm{KOH} / \mathrm{g}$ oil.

\subsubsection{Deactivation of $\mathrm{NaOCH}_{3}$ catalyst}

Since the $\mathrm{NaOCH}_{3}$ catalyst is in the solid state, it can be separated from the liquid mixture by filtration after the reaction. The activity of the used catalyst was measured to confirm whether the catalyst can be used repeatedly. The reactions using the fresh catalyst were performed using $1.5 \mathrm{wt} \%$ of the crystallized $\mathrm{NaOCH}_{3}$ catalyst at $85{ }^{\circ} \mathrm{C}$ for $2 \mathrm{~h}$ and at $45^{\circ} \mathrm{C}$ for $5 \mathrm{~h}$. The ratio of DMC to oil was 3:1. After filtration under reduced pressure, the solid on the filter was collected using a spatula and used for a second reaction. The temperature of the second batch reactions was $85^{\circ} \mathrm{C}$ in both cases.

The conversions of the reactions using the used catalyst were very low. This result means that the activity of the used catalyst sharply decreased during the first reaction regardless of the difference in the reaction temperature, and catalyst deactivation cannot be prevented by decreasing the reaction temperature.

On the other hand, when the used catalyst was dissolved in methanol and crystallized by a method proposed in this study, only a small decrease in catalytic activity was observed. Since the color of the catalyst changed from white to light brown during the reaction, deactivation could be caused by the adsorption of other components on the catalyst surface or transformation of $\mathrm{NaOCH}_{3}$ in contact with the reactant mixtures.

\section{Conclusions}

Fine and active catalyst particles were formed by the crystallization of $\mathrm{NaOCH}_{3}$ to produce biodiesel from canola oil and DMC. This method allowed the reaction to occur under mild conditions, but the catalyst could not be used repeatedly. Methanol 
conversion was above $96 \%$ when the catalyst amount was $2.0 \mathrm{wt} \%$, the molar ratio of DMC to oil was 3:1, and the reaction temperature was $65^{\circ} \mathrm{C}$. The conditions to establish high conversion were not affected by moisture when it was below $0.13 \mathrm{wt} \%$ or the acidic value when it was below $2.0 \mathrm{mg} \mathrm{KOH} / \mathrm{g}$ oil.

\section{Acknowledgment}

This work is supported by Japan Science and Technology Agency (JST), A-step feasibility study program (\#AS242Z01758L).

\section{References}

1. Ang, G.T., Tan, K.T., Lee, K.T., 2014. Recent development and economic analysis of glycerol-free processes via supercritical fluid transesterification for biodiesel production. Renewable Sustainable Energy Reviews 31, 61-70.

2. Ayoub, M., Abdullah, A.Z., 2012. Critical review on the current scenario and significance of crude glycerol resulting from biodiesel industry towards more sustainable renewable energy industry. Renew. Sust. Energy Rev. 16, 2671-2686.

3. Fabbri, D., Bevoni, V., Notari, M., Rivetti, F., 2007. Properties of a potential biofuel obtained from soybean oil by transmethylation with dimethyl carbonate. Fuel 86, 690-697.

4. Gharat, N., Rathod, V.K., 2013. Enzyme catalyzed transesterification of waste cooking oil with dimethyl carbonate. J. Mol. Catal. B: Enzym. 88, 36-40.

5. Go, A.R., Lee, Y., Kim, Y.H., Park, S., Choi, J., Lee, J., Han, S.O., Kim, S.W., Park, C., 2013. Enzymatic coproduction of biodiesel and glycerol carbonate from soybean oil in solvent-free system. Enzym. Microb. Technol. 53, 154-158. 
6. Ilham, Z., Saka, S., 2009. Dimethyl carbonate as potential reactant in non-catalytic biodiesel production by supercritical method. Bioresour. Technol. 100, 1793-1796.

7. Ilham, Z., Saka, S., 2010. Two-step supercritical dimethyl carbonate method for biodiesel production from Jatropha curcas oil. Bioresour. Technol. 101, 2735-2740.

8. Ilham, Z., Saka, S., 2011. Production of biodiesel with glycerol carbonate by noncatalytic supercritical dimethyl carbonate. Lipid Technol. 23, 10-13.

9. Ilham, Z., Saka, S., 2012. Optimization of supercritical dimethyl carbonate method for biodiesel production. Fuel 97, 670-677.

10. Jo, Y.J., Lee, O.K., Lee, E.Y., 2014. Dimethyl carbonate-mediated lipid extraction and lipase-catalyzed in situ transesterification for simultaneous preparation of fatty acid methyl esters and glycerol carbonate from Chlorella sp. KR-1 biomass. Bioresour. Technol. in press.

11. Jung, H., Lee, Y., Kim, D., Han, S.O., Kim, S.W., Lee, J., Kim, Y.H., Park, C., 2012. Enzymatic production of glycerol carbonate from by-product after biodiesel manufacturing process. Enzym. Microb. Technol. 51, 143-147.

12. Lee, O.K., Kim, Y.H., Na, J.G., Oh, Y.K., Lee, E.Y., 2013. Highly efficient extraction and lipase-catalyzed transesterification of triglycerides from Chlorella sp. KR-1 for production of biodiesel. Bioresour. Technol. 147, 240-245.

13. Min, J.Y., Lee, E.Y., 2011. Lipase-catalyzed simultaneous biosynthesis of biodiesel and glycerol carbonate from corn oil in dimethyl carbonate. Biotechnol. Lett. 33, $1789-1796$.

14. Notari, M., Rivetti, F., 2004. Use of a mixture of esters of fatty acids as fuel or solvent. Patent No. WO2004/052874. 
15. Panchal, B.M., Dhoot, S.B., Deshmukh, S.A., Sharma, M.R., Kachole, M.S., 2013. Production of DMC-BioD from Pongamia pinnata seed oil using dimethyl carbonate. Fuel 109, 201-205.

16. Seong, P.J., Jeon, B.W., Lee, M., Cho, D.H., Kim, D.K., Jung, K.S., Kim, S.W., Han, S.O., Kim, Y.H., Park, C., 2011. Enzymatic coproduction of biodiesel and glycerol carbonate from soybean oil and dimethyl carbonate. Enzym. Microb. Technol. 48, $505-509$.

17. Su, E., You, P., Wei, D., 2009. In situ lipase-catalyzed reactive extraction of oilseeds with short-chained dialkyl carbonates for biodiesel production, Bioresour. Technol. $100,5813-5817$.

18. Tan, K.T., Lee, K.T., Mohamed, A.R., 2010. Optimization of supercritical dimethyl carbonate (SCDMC) technology for the production of biodiesel and value-added glycerol carbonate. Fuel 89, 3833-3839.

19. Zhang, L., Sun, S., Xin, Z., Sheng, B., Liu, Q., 2010a. Synthesis and component confirmation of biodiesel from palm oil and dimethyl carbonate catalyzed by immobilized-lipase in solvent-free system. Fuel 89, 3960-3965.

20. Zhang, L., Sheng, B., Xin, Z., Liu, Q., Sun, S., 2010b. Kinetics of transesterification of palm oil and dimethyl carbonate for biodiesel production at the catalysis of heterogeneous base catalyst. Bioresour. Technol. 101, 8144-8150.

\section{Figure captions}

Fig. 1. Effect of catalyst amount on oil conversion for powdered sodium methoxide catalyst. Molar ratio of DMC to oil: 3 , temperature: $85^{\circ} \mathrm{C}$.

Fig. 2. Effect of molar ratio of DMC to oils on oil conversion (a), and effect of catalyst amount on conversion (b) for crystallized sodium methoxide catalyst. 
Figures

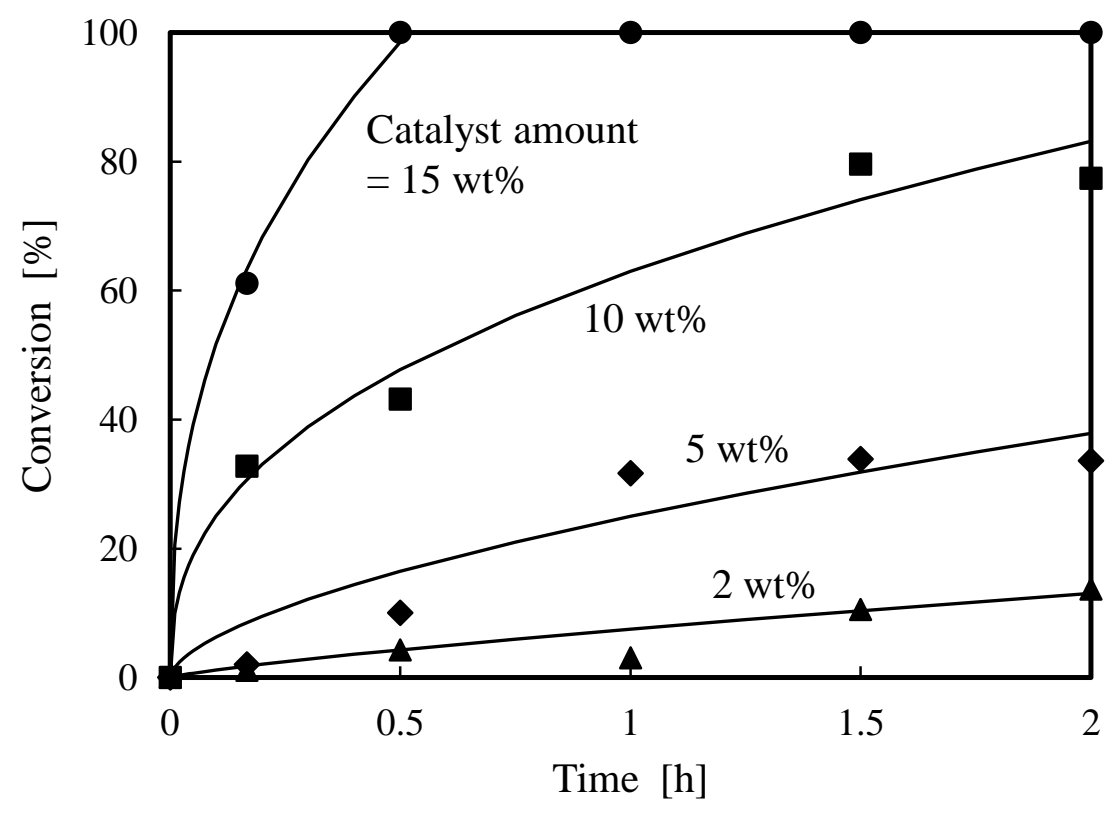

Fig. 1 Effect of catalyst amount on the conversion of oil for powdered sodium methoxide catalyst. Molar ratio of DMC to oil: 3 , temperature: $85^{\circ} \mathrm{C}$. 

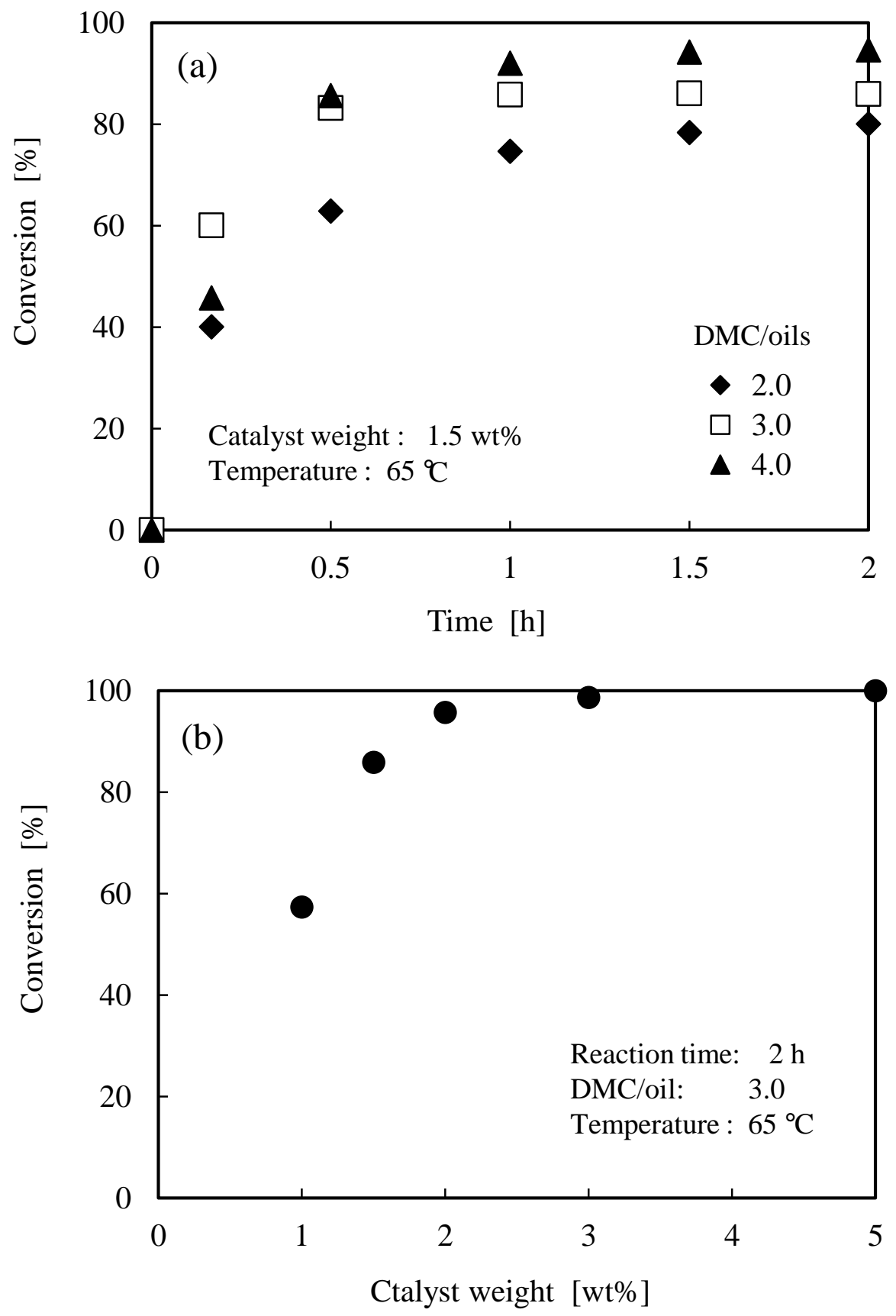

Fig. 2 Effect of molar ratio of DMC to oils on the oil conversion (a), and effect of catalyst amount on the conversion (b) for crystallized sodium methoxide catalyst. 